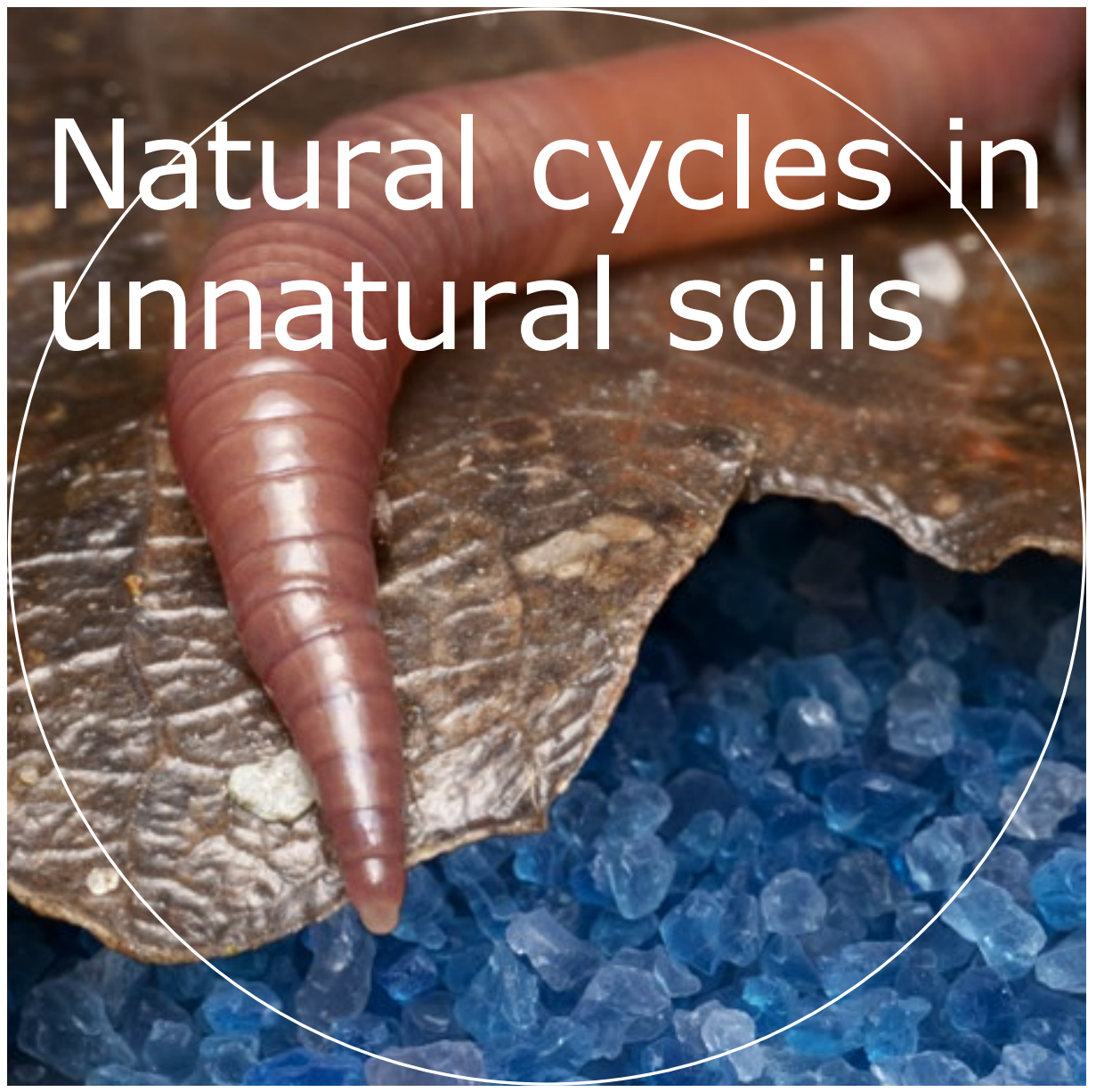

Prof. dr Jan Willem van Groenigen

Inaugural lecture upon taking up the position of Personal Professor of Soil Biogeochemistry at Wageningen University \& Research on 30 March 2017 


\section{Natural cycles in unnatural soils}

\section{Prof. dr Jan Willem van Groenigen}

Inaugural lecture upon taking up the position of Personal Professor of Soil Biogeochemistry at Wageningen University \& Research on 30 March 2017 
DOI HTTPS://DOI.ORG/10.18174/420698 ISBN 978-94-6343-650-2 


\section{Natural cycles in unnatural soils}

Esteemed Rector Magnificus; dear colleagues, students, friends and family,

\section{Introduction}

In the 2015 movie 'The Martian', Matt Damon plays the role of astronaut Mark Watney, who is left alone on the planet Mars after a dust storm forces his team mates to evacuate the planet prematurely. Left to his own devices, he has little food and even less chance of escape.

Fortunately, he does have the benefit of an excellent education. No, he is not a Wageningen soil scientist; life is never that good. But he is the next best thing: a botanist. So he should be able to grow his own food. There is only one problem: NASA appears to have sent a botanist to Mars without also sending some plant seeds with him. Fortunately, in another rather unlikely plot-twist, the Thanksgiving meal contains live potatoes, and our botanist goes to work. He builds a greenhouse, and produces water - in notorious short supply on Mars - using an ingenious technique. Of course he meets several problems, as it goes in movies like these, not in the least when his greenhouse breaks down and his crop freezes to death. Yet, in the end he not only manages to survive but even to return safely to planet Earth.

When I saw this movie, I did not only see an exciting Science-Fiction movie playing in the not-so-distant future: I also saw what I would like to call an 'allegory for modern agriculture'. I am not sure whether that was what the director intended, but that is what I saw. 


\section{An allegory for modern agriculture}

The movie reminded me especially of the period in the first half of the previous century that is now commonly called the 'Dust Bowl'. At that time, large parts of the North-American prairies were devastated due to a combination of crippling agricultural problems. If you compare the pictures from the Dust Bowl with those from the movie, you may understand my association (Figure 1).
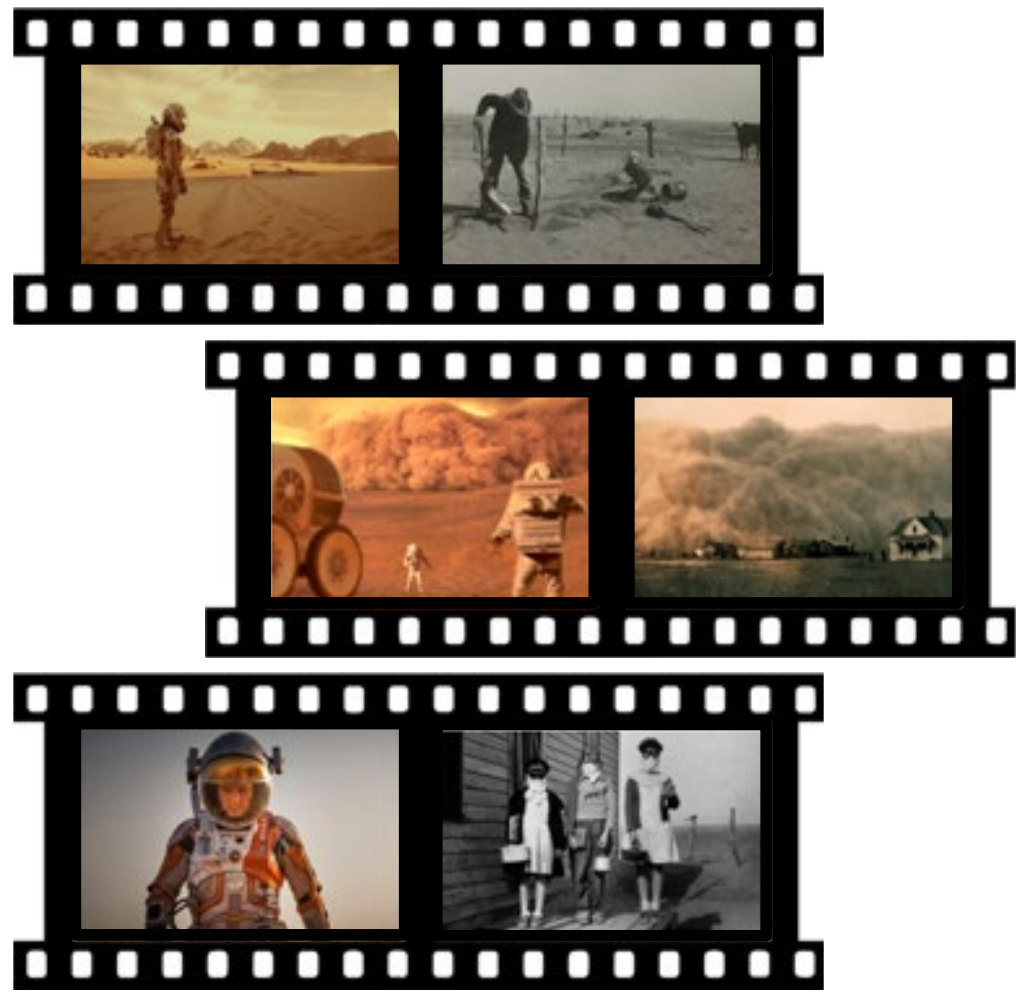

Figure 1. Similarities between the 2015 movie 'The Martian' (left) and the Dust Bowl in the 1930s (right)

The main cause for the Dust Bowl was, without a doubt, shortage of water, caused by extended periods of drought over several years; definitely something that Mark Watney on Mars could relate to. The second cause for the Dust Bowl was monoculture farming and a lack of crop rotation; also quite familiar to our astronaut. These two causes resulted in a serious loss of fertile topsoil by wind erosion. As a consequence, soils had very little organic matter; again a problem Mark Watney 
encountered on Mars. Even the pictures from the dust storms in the 1930s look eerily similar to those from the movie.

I could go on and find more similarities: the protective masks against the dust look very much like space masks, and in a way Mark Watney also encountered climate change as a very serious danger to his agroecosystem, although admittedly in a very different way than we are currently experiencing on earth.

However, much more important than the similarities between the Dust Bowl and 'The Martian' are their differences. The most striking difference is that, unlike Mark Watney, we do not have the luxury of a spaceship that will help us escape our problems and find a better place. We will have to deal with our problems on our planet, on Earth.

And modern agriculture faces serious problems indeed. In addition to the ones I have just mentioned, we managed to create a number of extra ones, mainly because we are with so many people on our planet - more people than ever before. Here I plotted the trend in global population over the last 60-70 years or so in orange, and the amount of global fertilizer production (mainly nitrogen and phosphorus) in green (Figure 2). Both trends are very much alike, for good reasons: we have more and more mouths to feed, and therefore we have to continuously increase our agricultural yields. Increasing yield on a large scale cannot be done without large amounts of fertilizer - it is simply impossible.

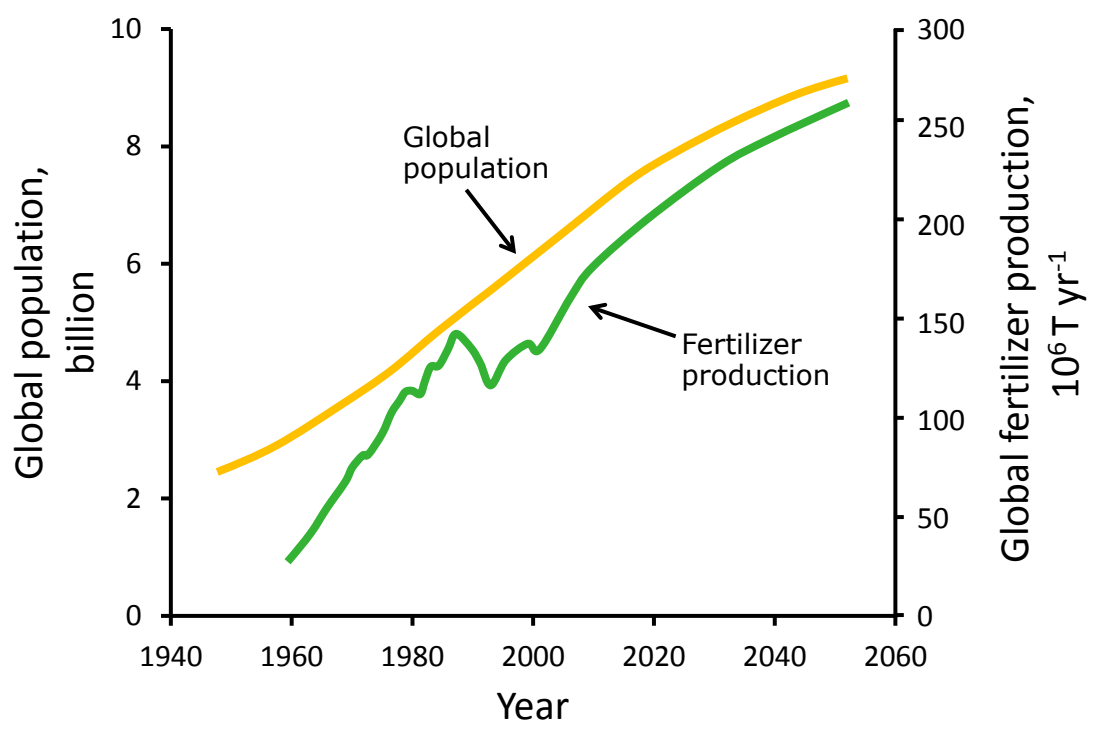

Figure 2. Trends in global population and global fertilizer production (FAO, 2012). 
However, these large amounts of fertilizer have also caused a lot of problems. In their seminal paper, Rockström et al. (2009) defined nine planetary boundaries with respect to the environment that mankind is in danger of exceeding (Figure 3). I would like to draw your attention to 'Biogeochemical flows of phosphorus and nitrogen' this essentially denotes losses of fertilizer from agriculture to the environment. It is one out of two planetary boundaries which we have already exceeded according to the authors. They estimate that we would have to reduce the inputs of nitrogen and phosphorus with approximately $50 \%$ to return within our planetary boundaries. This is, evidently, a striking challenge if we still want to feed the ever-increasing number of mouths.

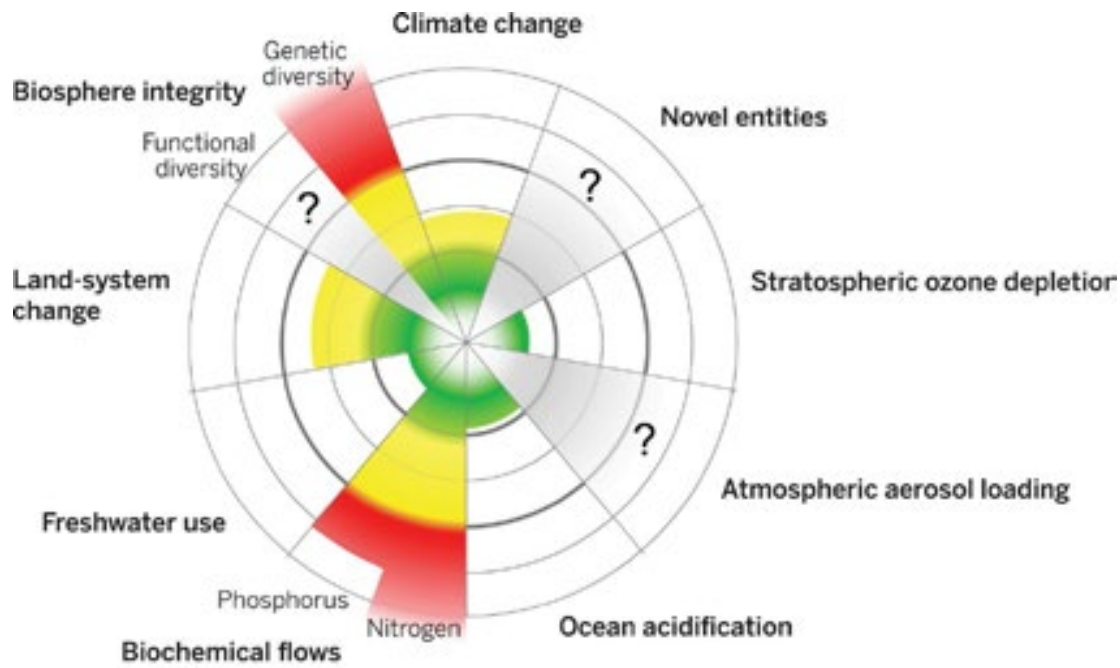

Beyond zone of uncertainty (high risk)

Below boundary (safe)

In zone of uncertainty (increasing risk)

\section{Boundary not yet quantified}

Figure 3. Defining a safe operating space for humanity: nine 'planetary boundaries' that mankind should not exceed (Rockström et al. 2009).

But it is necessary, because all these losses of nitrogen and phosphorus to the environment cause tremendous problems. Eutrophication of surface water is one problem; all sorts of compounds leaching to groundwater is another; as well as gaseous losses to the atmosphere, such as emissions of greenhouse gases and ammonia.

Besides environmental pollution, there is another reason to be much more efficient with our nutrients: not all of them are infinitely available. Phosphorus is produced 
from rock phosphate in mines, and it is estimated that we will reach 'peak phosphate' sometime within the next decades. After reaching this 'peak', rock phosphate reserves will be decreasing and phosphate fertilizers will become more expensive.

In conclusion, there are very good reasons to be much, much more efficient with nutrients in our agricultural systems.

\section{The beneficial role of soil biota in agriculture}

Fortunately, on Earth we also have a number of advantages over the planet Mars. You may have noticed that the planets look slightly different: there is a lot of blue on our planet: water. And there is a lot of green on our planet: those are plants, biota.

Generally, I do not study biota aboveground, but belowground: plant roots as well as other soil biota. I study 'Natural cycles in unnatural soils', i.e. how soil biota affect the cycles of Nitrogen and Phosphorus in unnatural, agricultural soils. In my research I address two main questions:

1 How do soil biota affect nutrient cycles in these intensively managed systems?

and

2 Can they help to make agriculture more sustainable?

I am very lucky to be an ecologist working in the soil, because soil is often considered the "final frontier in ecology" (Science, 2004). If you want to travel to the largest unexplored pool of biodiversity on Earth, you should not take a submarine to dive deep into a canyon in the Pacific Ocean; you should not go to the Amazon to study the rainforest; instead, you should take a shovel and dig a few decimetres deep. There is more discovered life in soil than anywhere else on earth, and there is more undiscovered life in soil than anywhere else on earth.

In my research I study the role of soil life, and I focus to a large extent on the role of soil fauna: critters. To illustrate the importance of those critters for soil functioning, we made a time-lapse movie ( $h$ ttps://vimeo.com/222168889). What you can see here are two compartments, both filled with a simulated soil profile and with a layer of leaves on top. Both compartments contain microbiota such as bacteria and fungi, but only one of them contains fauna, and I will leave it up to you to guess which one that is. What you will see over the course of one minute is one month of activity in these two compartments. There it goes...

I think you are able to see some activity in the left compartment. If you look carefully, you see blue puffs popping up that you may recognize from when you leave your bread in the cupboard for too long - those are fungi. But I hope you will agree with me that there is much more activity in the right compartment, indeed the 


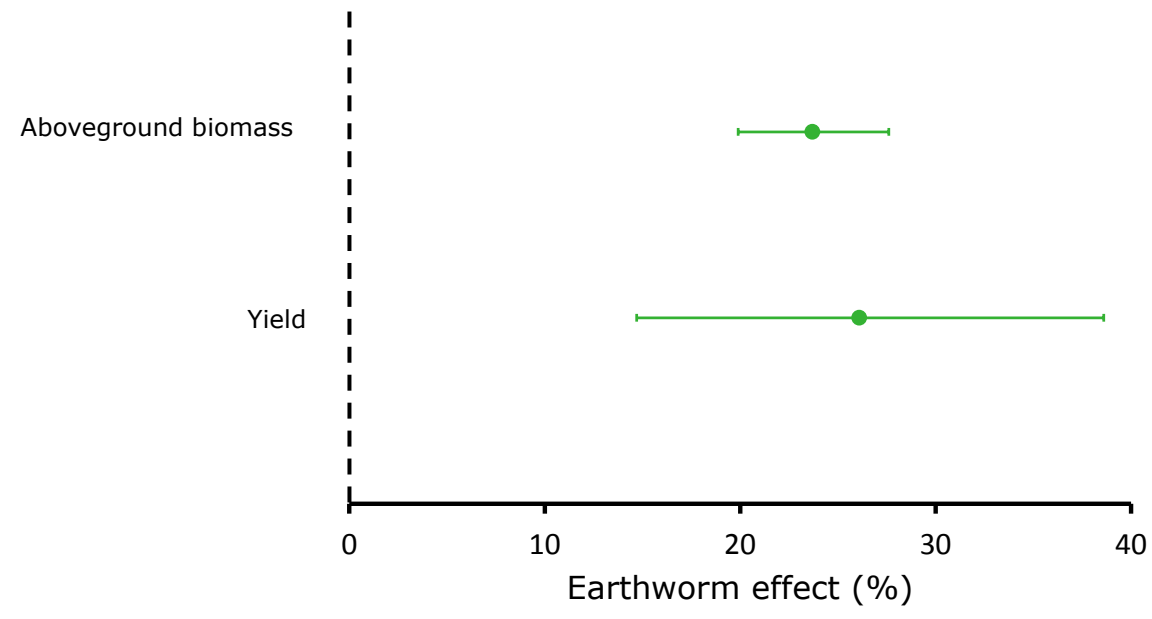

Figure 4. Effects of earthworm presence on plant production: results from a meta-analysis

(Van Groenigen et al. 2014). Error bars denote the 95\% confidence interval..

one with the soil fauna: there are earthworms in there, as well as potworms, isopods, springtails, mites and other micro-arthropods. At this scale, most of the activity that you see is caused by earthworms: they eat the leaves, make them smaller and drag them into the soil. Altogether, earthworms increase decomposition of the leaves. If I were to zoom in, I would be able to show you similar activity by potworms and other soil fauna.

You can imagine that the increased decomposition of leaves has an enormous impact on the soil. There are nutrients in the leaves, and they are now being released and made available to plants much quicker. Earthworms and other fauna therefore make soil more fertile.

A perfect illustration of this earthworm effect is a study that I published together with Ingrid Lubbers, Hannah Vos and other colleagues a few years ago (Van Groenigen et al., 2014). It is a meta-analysis, which means that we combined data of all papers published by research groups around the world on a certain topic - in this case, the effect of earthworms on crop yield. The results showed us that, if earthworms are present in the soil, aboveground biomass production increases on average with $24 \%$, and crop yield with $26 \%$ (Figure 4). It is no secret that earthworms are my petorganisms - and now it turns out that they increase yield by one quarter! That is truly an amazing number.

Another example of how important biota can be in improving the functioning of agricultural systems is from some time ago, when I was a postdoctoral researcher in California and studied rice systems. California rice systems are among the most productive in the world, but they are also associated with many environmental 
problems. Water shortage, for example, is always a problem in California, but also air quality. Rice produces a lot of straw, and there is not much you can use rice straw for, so farmers traditionally burned it to quickly release its nutrients. However, as this caused serious air quality problems rice straw burning became prohibited. As a result, the farmers started to superficially flood their rice fields during winter instead, to remedy the drought and to increase decomposition of the straw before the next growing season. Interestingly, these flooded rice fields became a very important wintering habitat for migrating waterfowl coming all the way from Alaska and Siberia. In the past, the waterfowl wintered in swamps in the California Central Valley, but those had disappeared with the onset of agriculture in California. Now, all of a sudden, a similar and suitable habitat was created.

In my research project I studied the effect of these wintering waterfowl on the rice production system. The first thing I did was set up a large transect across the Central Valley. Across this transect, we established pairs of plots of three by three metres in farmers' fields. In one of the plots the waterfowl were able to enter, but from the other one they were excluded. By the end of the winter we returned and measured how much straw was left. As you can see in the left part of Figure 5, when waterfowl were allowed inside the plot, there was half as much straw left as when the waterfowl were excluded (Van Groenigen et al., 2003). This was very good news because the straw had been decomposed due to waterfowl activity.

But it did not stop there. The waterfowl did not come to eat straw, they came because they eat seeds: rice seeds as well as weed seeds. So when we came back during the next rice harvest and measured weed pressure in those plots, we found that grassy weed pressure was more than $50 \%$ reduced due to waterfowl activity in the preceding winter (right side of Figure 5). I think this is a very powerful illustration of how important and beneficial biota can be in agricultural systems.
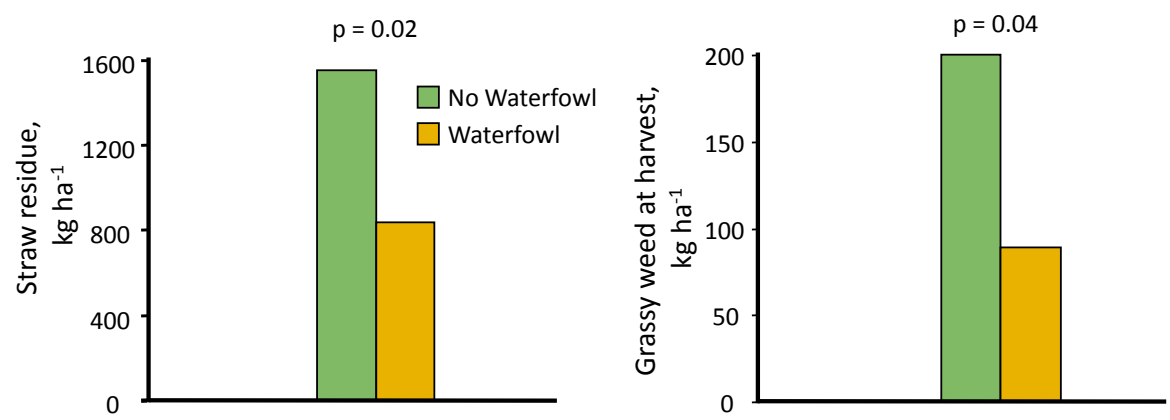

Figure 5. Effects of foraging waterfowl in winter-flooded rice fields in the California Central Valley on straw decomposition during the winter (left) and on grassy weed pressure in the subsequent rice crop (right) (Van Groenigen et al. 2003). 


\section{Nature versus agriculture}

However, I think that we as soil ecologists should be careful to state that agriculture should mimic natural systems as much as possible; this seems to be implied sometimes when we say that we should "learn from nature". Nature is beautiful; nature is endlessly fascinating; it is something to admire and something to study. Nature is a marvel to walk through... but it is a nightmare to be part of.... Because nature is also ruthless; it is a-moral, and, most importantly of all in this context, nature never ever gives away a free lunch.

The German philosopher Arthur Schopenhauer wrote that it is exactly our ability to rise above the base laws of nature that is the essence of what makes us human. Similarly, I think that in many ways the capacity to bend, to transcend the rules of nature is the essence of modern agriculture.

As soil ecologists working in agriculture we should be inspired by nature and use our knowledge wherever possible to improve our agricultural systems. We should be inspired by nature, but not blinded by it, because there are many instances where the rules of nature do not translate so well to agriculture. Where benefits of biota are much smaller than they are in nature; or where those benefits even become downsides; or, most fascinating perhaps, where biota in agriculture can perform novel beneficial roles that are not possible or prominent in nature. It is these shifting roles of soil biota in agriculture that I intend to study - as a soil ecologist I am fascinated more by the differences between agriculture and nature, than by their similarities.

To do that, I need to work closely with experts on other aspects of agricultural systems: with agronomists, soil chemists and soil physicists. Only by collaboration can we fully utilize the potential of ecology in agricultural systems. In the next section of my lecture, I will give four examples of the shifting roles of soil biota.

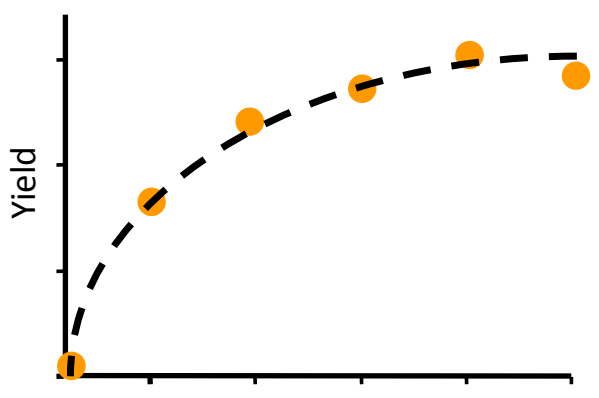

\# of plant species
Figure 6. The classical 'diversity - productivity' relation), here expressed as the relation between number of grass species and aboveground productivity in grassland. 


\section{Shifting roles of soil biota in agriculture}

\section{(i) Biodiversity-agroecosystem functioning relationships}

The first example is connected with the well-known 'diversity-productivity relation' I show in Figure 6. The x-axis plots the number of plants in, let's say, a grassland. The $y$-axis represents the productivity of this grassland; its yield. This relation is almost a paradigm in ecology: if you have more species, you have more productivity. This has been repeatedly shown for natural and semi-natural grasslands.

Yet, this relation has not been extensively studied or conclusively proven in intensively managed systems. Those systems are very different; they get many nutrients applied as fertilizer or manure, and typically the extent of plant biodiversity is very limited as farmers only seed one, two, or maybe three species. In his $\mathrm{PhD}$ research, Diego Abalos studied the relation between grass species diversity and agroecosystem functioning in intensively managed grasslands. He used four species that are fairly common in such grasslands and he experimented with different combinations of those species: a very low level of biodiversity for an ecologist, but a realistic level of biodiversity for an agronomist.

His results are shown in Figure 7 (Abalos et al., 2014). The lower left four bars depict the aboveground yields of the four monocultures. To the right of these are all combinations of two species, and one bar for the treatment with all four species. The first thing that stands out here is that more species does not mean more productivity. In fact, the highest producing treatment is the bar on the left, which is a monoculture of Lolium perenne (L.), 'Engels raaigras' in Dutch. This also happens to be the species most commonly seeded by Dutch farmers - and for good reason, because farmers know this.

For intensively managed systems, the potential of increasing diversity to boost productivity is very limited. However, I do think that there are other benefits from the limited amount of plant biodiversity that we can impose in such systems. This can be illustrated by the greenhouse gas emissions Diego measured in his experiment: emissions of nitrous oxide $\left(\mathrm{N}_{2} \mathrm{O}\right)$, a very strong greenhouse gas. These emissions are shown in the upper half of Figure 7 , and you can see that the grassland community composition affects the $\mathrm{N}_{2} \mathrm{O}$ emissions very strongly. I would like to draw your attention to the community with the lowest $\mathrm{N}_{2} \mathrm{O}$ emission, which is a combination of two grass species: L. perenne and P. Trivialis (L.). If you look at the monocultures of those two grass species, you can see that yield in the mixture of two species lies around the average of the two monocultures. However, $\mathrm{N}_{2} \mathrm{O}$ emissions are significantly smaller than either of the monocultures. So, there can be benefits of having combinations of grass species in managed agroecosystems that we don't fully understand yet.

Fortunately, Diego is still studying this topic, now as a Marie Skłodowska-Curie scholar in my group. He has set up a series of greenhouse and field experiments, and 
I'm looking forward to seeing his results in the coming years. Eventually, we hope that his results can help us understand how we can make heavily managed agroecosystems more sustainable using modest yet realistic levels of imposed biodiversity.

\section{(ii) Effects of soil fauna on plant growth}

The second example of shifting roles of soil biota in intensively managed systems is illustrated by the graph that I already showed before in Figure 4. You remember this amazing result: my pet organism, earthworms, increases plant yield with a quarter! Well... yes and no... We studied the data-set underlying this meta-analysis in-depth, and the first thing we did was split up the dataset for different plants groups. You can see the results of this exercise in Figure 8. At the bottom you see the pasture grasses - and yes, earthworms increase their yield with approximately $25 \%$. In the middle you can see the grain crops: wheat, barley, maize, rice, etc. They are even more

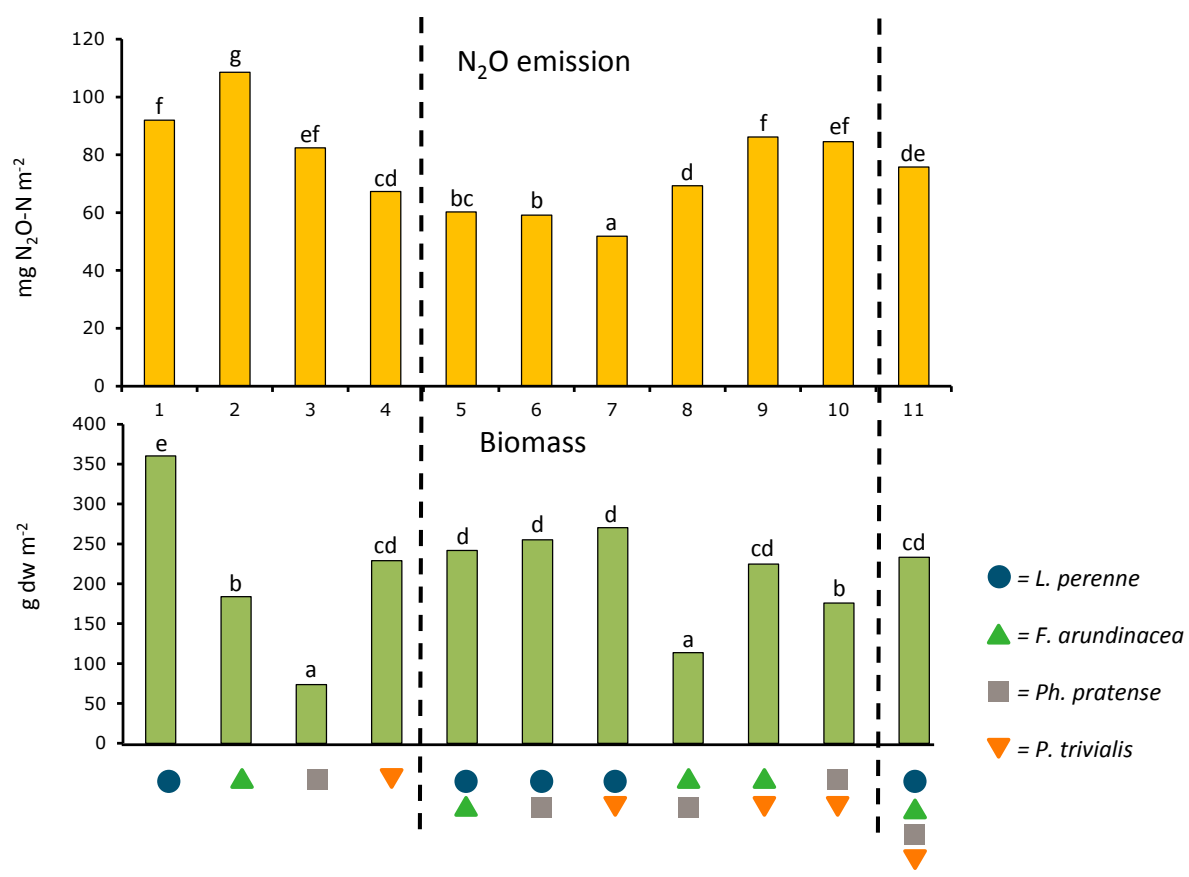

Figure 7. Grass productivity and $\mathrm{N}_{2} \mathrm{O}$ emissions as affected by grassland species composition. Results from a 42 day greenhouse study with four common species in intensively managed pastures. Columns were amended with artificial urine, applied at a rate of $400 \mathrm{~kg} \mathrm{~N} \mathrm{ha-1}$ (Abalos et al., 2014). Different characters denote significant differences with $p<0.05$. 
beneficially affected by earthworms; over $30 \%$ ! However, on top you see the legumes, such as clover, peanut and soybean. We know that legumes are very special: they can fixate nitrogen from the air. So in a way, they can produce their own Nitrogen fertilizer. But now, all of a sudden, the effect of earthworms on yield ceases to be significant...

Looking for an explanation, we again split up our dataset in systems that did receive substantial amounts of nitrogen fertilizer and those that received nothing or very little. As soon as we did that (right side of Figure 8), we saw that the effect of earthworms ceased to be significant when substantial amounts of Nitrogen were applied. So, yes, earthworms can have a strong beneficial effect on yield, but only in marginal systems: in poor systems. Not in conventional agroecosystems like we have in the Netherlands, and perhaps not even in our organic agroecosystems.

(iii) Effects of soil fauna on greenhouse gas emissions

The story becomes even more complicated: earthworms can actually be harmful to the environment. In his introduction, the rector already alluded to a paper that we published a few years ago with Ingrid Lubbers in the journal 'Nature Climate Change' (Lubbers et al., 2013). It was a meta-analysis again, so we analysed all papers published by groups around the world on a certain topic - in this case the effect of earthworm presence on greenhouse gas emissions from the soil. We found that, on average, emissions of the potent greenhouse gas $\mathrm{N}_{2} \mathrm{O}$ increased by $33 \%$.

As you can imagine, this was a rather shocking finding, especially for soil ecologists. Over the last few years we have studied the mechanisms behind this effect in detail, also studying the effects of other fauna on $\mathrm{N}_{2} \mathrm{O}$ : potworms, springtails, isopods etc. From our most recent studies a picture emerges in which the biodiversity of all these soil critters affect $\mathrm{N}_{2} \mathrm{O}$ emissions. It seems likely that, if we have a high
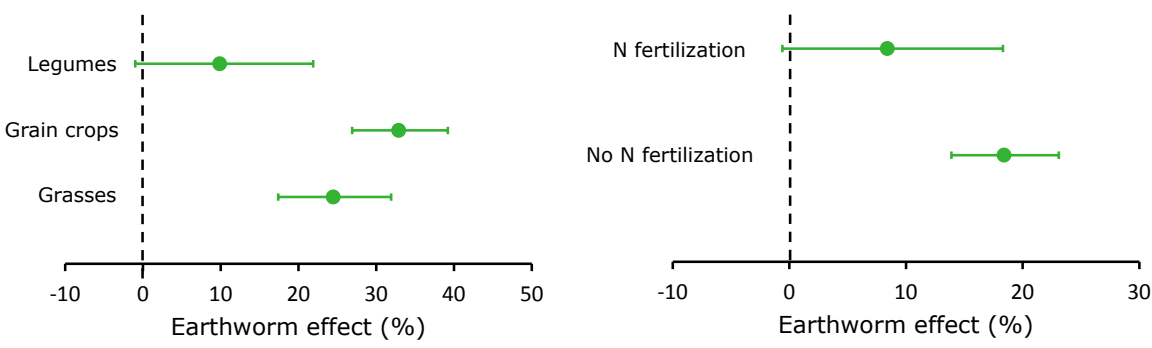

Figure 8. Effects of earthworm presence on aboveground biomass: results from a meta-analysis. Results sorted according to plant group (left) and level of Nitrogen fertilization (right). "No fertilization" indicates inputs by fertilizer, residue or manure less than $30 \mathrm{~kg} \mathrm{~N} \mathrm{ha}^{-1} \mathrm{yr}^{-1}$ (Van Groenigen et al., 2014). Error bars denote the $95 \%$ confidence interval. 
biodiversity of soil fauna, emissions of $\mathrm{N}_{2} \mathrm{O}$ will go down. I hope I will be able to report good news about this topic in the near future.

At Wageningen University and Research we have a number of advanced tools to study the mechanisms underlying the relation between soil fauna and $\mathrm{N}_{2} \mathrm{O}$ emission. An important facility is the excellent $X$-ray micro tomography scanner that we have on campus. This technique allows us to see inside the soil, to study and quantify what effects fauna have on soil structure. Figure 9 shows two such scans, derived from the master thesis research of Rima Porre (Porre et al., 2016). Both are scans of soil cores of about $5 \times 10 \mathrm{~cm}$.

All the blue that you can see are pores filled with air - the pores that make exchange of oxygen, but also nitrous oxide or carbon dioxide, between the soil and the atmosphere possible. Both soil cores contain microbes, but only the core on the right contains potworms as well. I assume you can see that, due to the presence of the potworms, the soil structure radically changes: many more air-filled pores that are much better connected to the atmosphere. I think that it's not difficult to imagine that this must lead to a larger gas exchange with the atmosphere. However, we need quantitative analysis of this data, and in the coming years I hope to cooperate closely with soil physicists to model the effects of soil fauna on gas diffusivity in the soil, in order to better understand their effects on greenhouse gas emissions.

(iv) Effects of earthworms on phosphorus availability

The fourth and last example of shifting roles of soil fauna in agricultural systems is about phosphorus. A few years ago we started to measure phosphorus in the
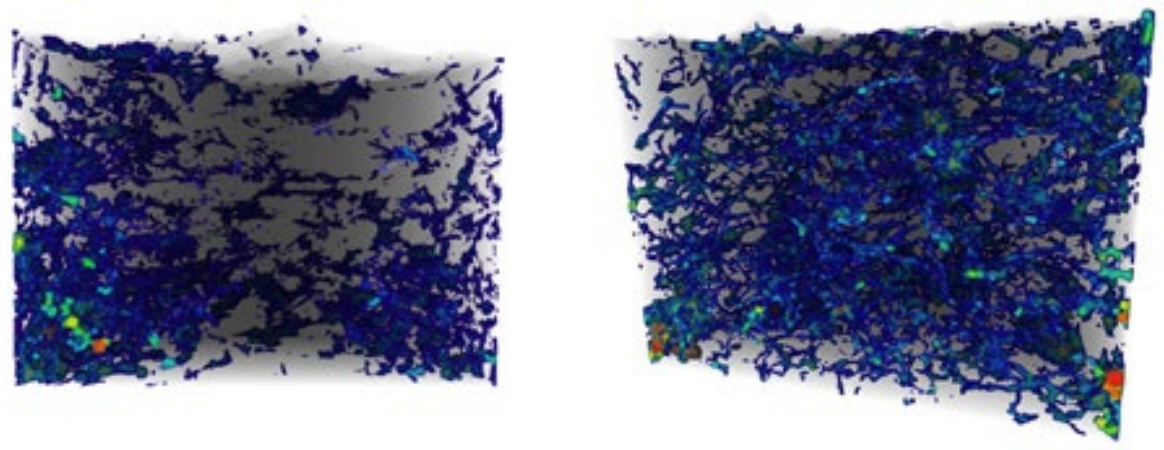

Figure 9. X-ray micro tomography scans from a soil core without (left) and with (right) potworms present (microbiota included in both cores). Both soil cores have residues incorporated as a food source. Core dimensions were $6.7 \mathrm{~cm}$ diameter and $5 \mathrm{~cm}$ height. Color-coded areas denote air-filled pores (Porre et al., 2016). 
droppings, the casts, of earthworms. In her MSc thesis research, Hannah Vos found that the concentration of plant-available phosphorus in those casts can be very high compared to the surrounding bulk soil - up to a factor 100 or 1000 higher (left side of Figure 10; Vos et al., 2014). That is a very remarkable effect, but what is even more spectacular is that plants can benefit from this increase in phosphorus availability. On the right side of Figure 1o you can see that plants, when they are fertilized with all necessary nutrients except for phosphorus, can grow 10-15\% better due to earthworm-induced increased phosphorus availability. A potentially very important pathway, especially in relation to the prospect of 'Peak phosphate'.

Naturally we were interested in the mechanisms behind this effect. If you are an ecologist studying (semi-)natural systems, the first pathway you may think about is the one on the left side of Figure 11: earthworms stimulate decomposition of organic matter. Organic matter contains phosphorus, and increased decomposition of organic matter leads to increased mineralization of phosphorus in the soil, and ultimately to increased uptake by plants. A very classic pathway in ecology.

However, in our study we found that another, hitherto not described, pathway might be much more important. This pathway was suggested by soil chemists, with whom we cooperate closely in this project. It is depicted on the right side of Figure 11: you can see another large pool of phosphorus, inorganic phosphorus that is a remnant of past applications of fertilizer and manure and is now chemically bound to soil particles and as such unavailable for plants. In the Netherlands this pool is large enough to sustain plant growth for 30 or so years - agronomists call it 'Legacy phosphorus'.
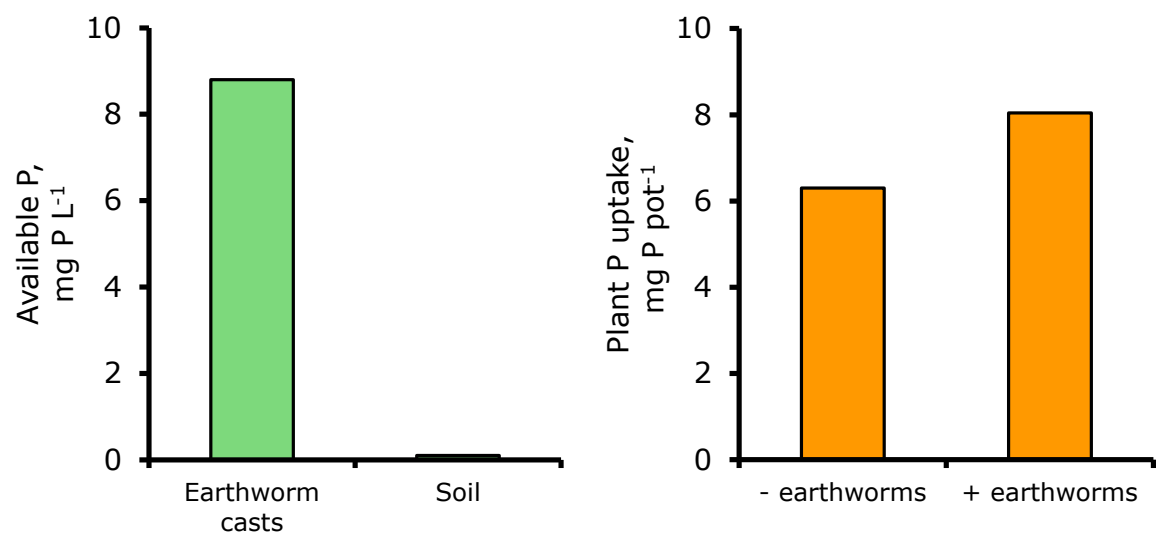

Figure 10. Effects of earthworms on phosphorus $(P)$ availability in soils with little available phosporus. Differences between ortho-P concentrations in a 1:10 soil:water extract in earthworm casts of L. terrestris vs. the bulk soil (left); P uptake by columns planted with L. multiflorum in soil fertilized with all nutrients except $P$ (right) (Vos et al., 2014; Ros et al., 2017). 


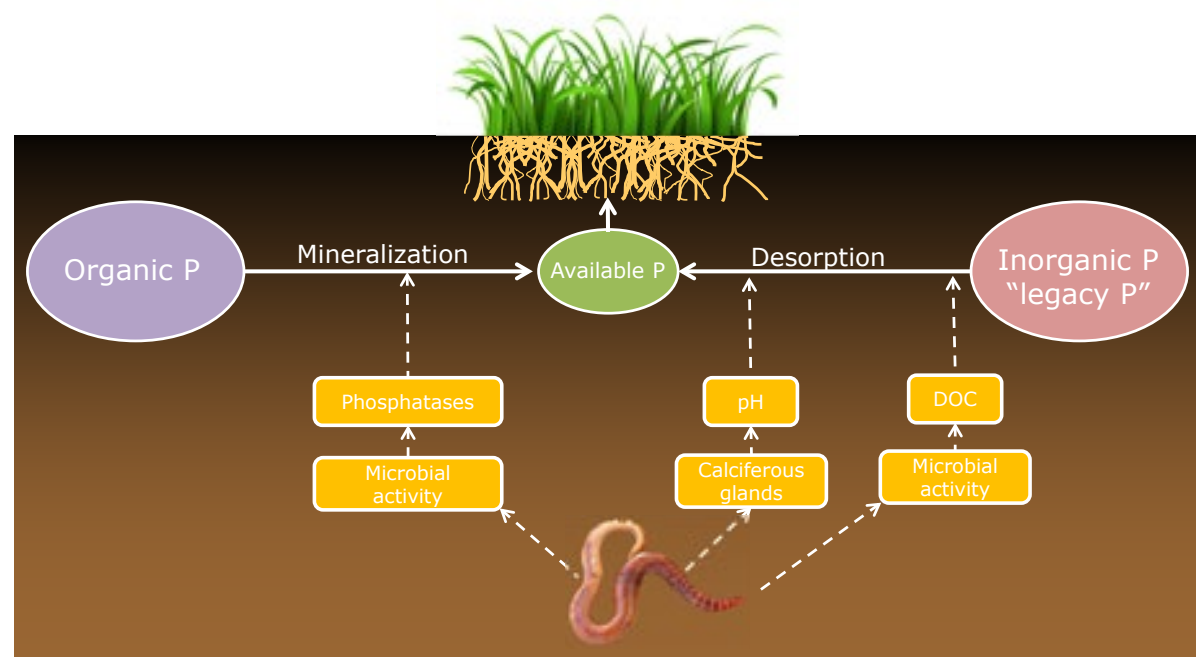

Figure 11. Pathways through which earthworm activity might increase phosphorus $(P)$ availability to plants: increase mineralization of organic phosphorus (left), and increased desorption of inorganic 'legacy' phosphorus (right).

In our proposed pathway, 'Dissolved Organic Carbon' or 'DOC' is the keyword. DOC is negatively charged, and can therefore compete for the same binding sites on soil particles as phosphorus, which is also negatively charged. As DOC levels in earthworm casts are strongly elevated compared to those in the bulk soil, this surplus of DOC forces phosphorus to desorb from the soil particles. In this way the phosphorus becomes available for plant uptake - a novel pathway that was not previously considered in earthworm studies. Mart Ros, in his PhD research, has recently shown together with MSc student Anupol Chareesri that you can model this increase in phosphorus availability using advanced surface complexation modelling (Ros et al., 2017). You can see this result in Figure 12, where on the x-axis the measured phosphorus concentration in casts and the bulk soil is shown, and on the $y$-axis the modelled concentration - a very good fit.

In the coming years Hannah Vos, now a PhD student, will look further into this pathway. She will look especially at the effect of earthworm diversity. Does phosphorus availability increase in the casts of all earthworm species, or perhaps only in the casts of one specific species? Or are different earthworms producing very different casts and might there be an optimal combination of species for maximizing phosphorus availability? Her first results, collected together with MSc student Lieke Beezemer, came in just a few weeks ago.

For her experimental work, Lieke collected as many different earthworm species as she could find in the Netherlands. In theory there are about 20 species of earthworms occurring in the Netherlands, but Lieke went into the field and fought 
the "slings and arrows of outrageous fortune" to come back with 10 different earthworm species for her experiments - a very difficult undertaking indeed. She determined the cast composition of these different species, and you can see the results in Figure 13. Unfortunately only for seven species results are shown, as one day before the start of the experiment three species decided to die collectively.

Nevertheless, I think that the results are very interesting - at the bottom you can see the DOC concentration in the casts, and you can see that all casts have higher DOC levels than the bulk soil, but also that they differ significantly among themselves. Lieke also measured plant available phosphorus, which is shown at the top of the figure. Again, concentrations in the soil are very low, and much higher in the casts of all earthworm species, with large differences among earthworm species. So, it seems important indeed to study the effect of earthworm species composition on plant available phosphorus.

\section{A hotel and a charming contest}

In the coming years, Hannah will study the effects of many earthworm species on phosphorus availability in detail, but it will be impossible for her to go into the field

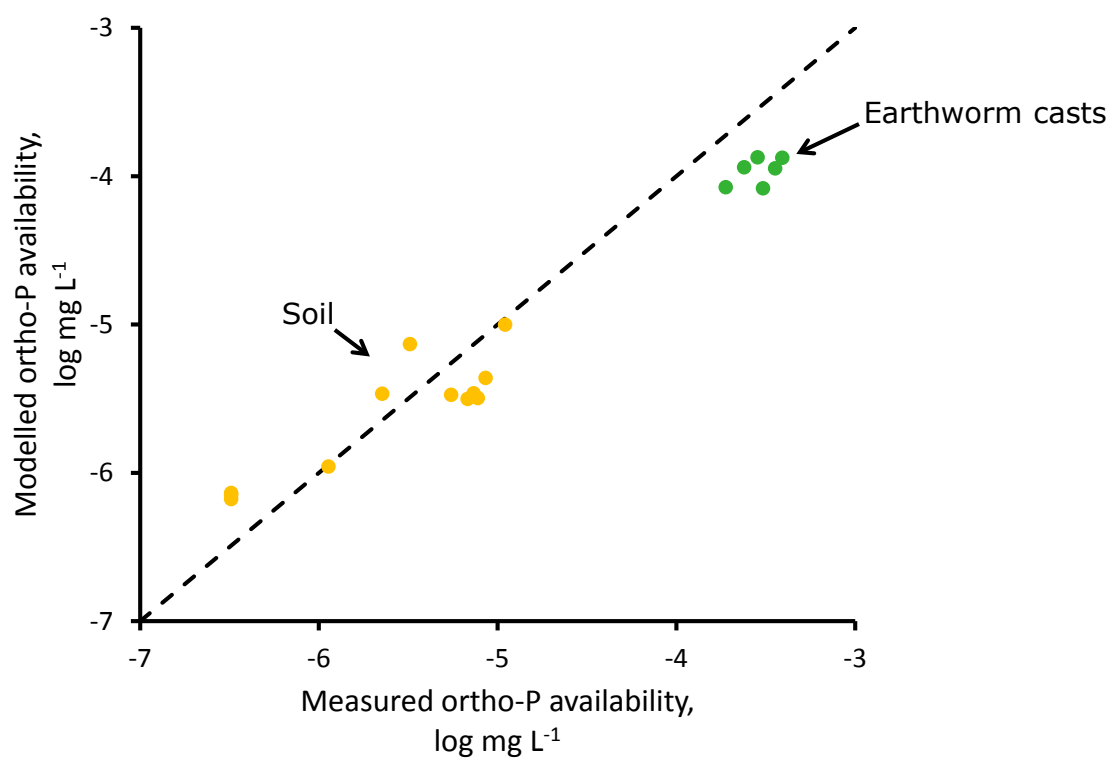

Figure 12. Measured vs modelled concentration of inorganic $P$ in soil extract (measured in a 1:10 soil:water solution) for soil samples and earthworm casts, taking into account increased concentrations of DOC in earthworm casts. The dotted line indicates the 1:1 relation. Details of the (surface-complexation) modelling with the CD-MUSIC model reported in Ros et al. (2017). 

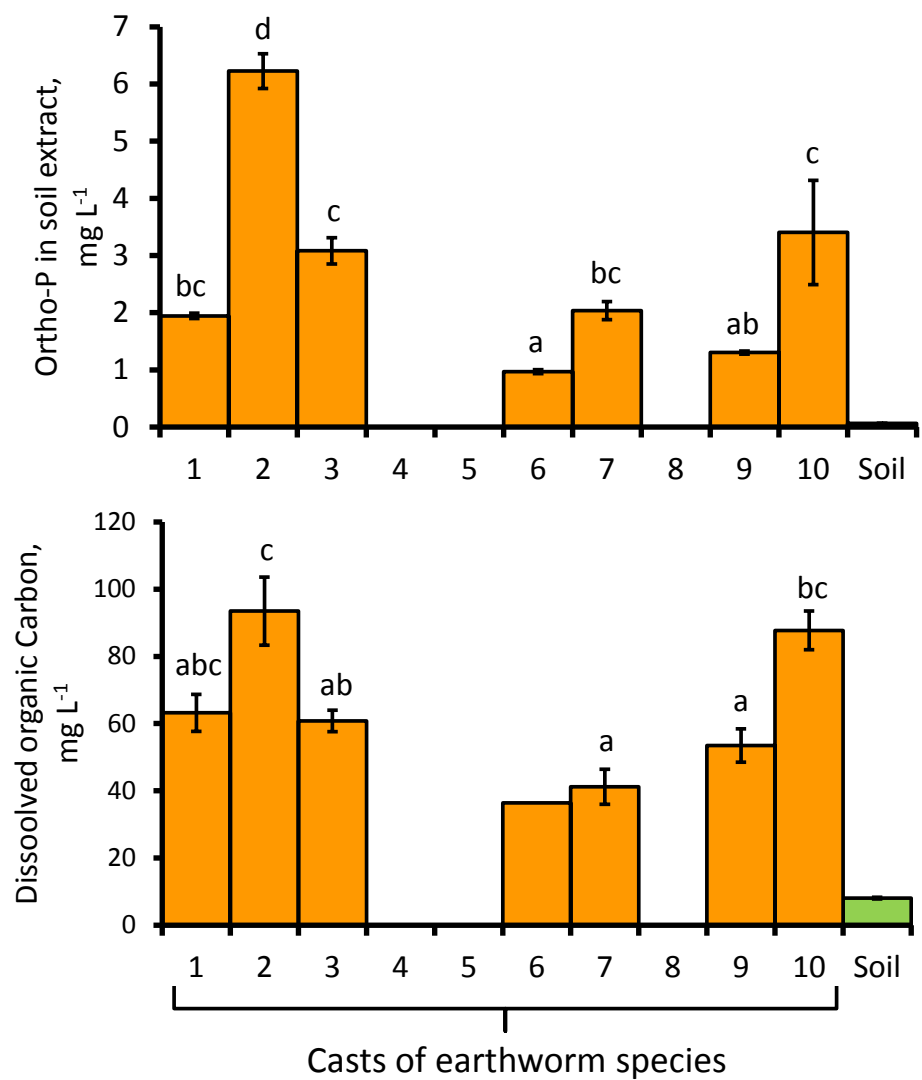

Figure 13. Dissolved organic carbon and ortho-P concentrations (both measured in a 1:10 soil:water solution) in casts of seven earthworm species as well as the bulk soil. Different characters denote significant differences with $p<0.05$ (Vos et al., 2017)

each time and collect them all. Therefore, we need a facility where we have easy access to a large number of different earthworm species. Recently we started building such a facility and we are calling it our 'Earthworm Hotel'. It is a unique facility - I do not think there is anything like it elsewhere on Earth - and it will undoubtedly be very valuable to our research. For this reason its current name is also rather grandiose: 'Hotel Caliwormia'. I am confident that this earthworm hotel will not only help us considerably in our research, but will also prove to be an excellent way to communicate the importance of our work to the general public.

There is another way in which we try to reach the general public: I'm very proud to announce the first ever 'Wageningen Worm Charming Championship', to be held next month. Earthworm charming is the noble art of attracting earthworms from the soil 


\section{Thank you!}
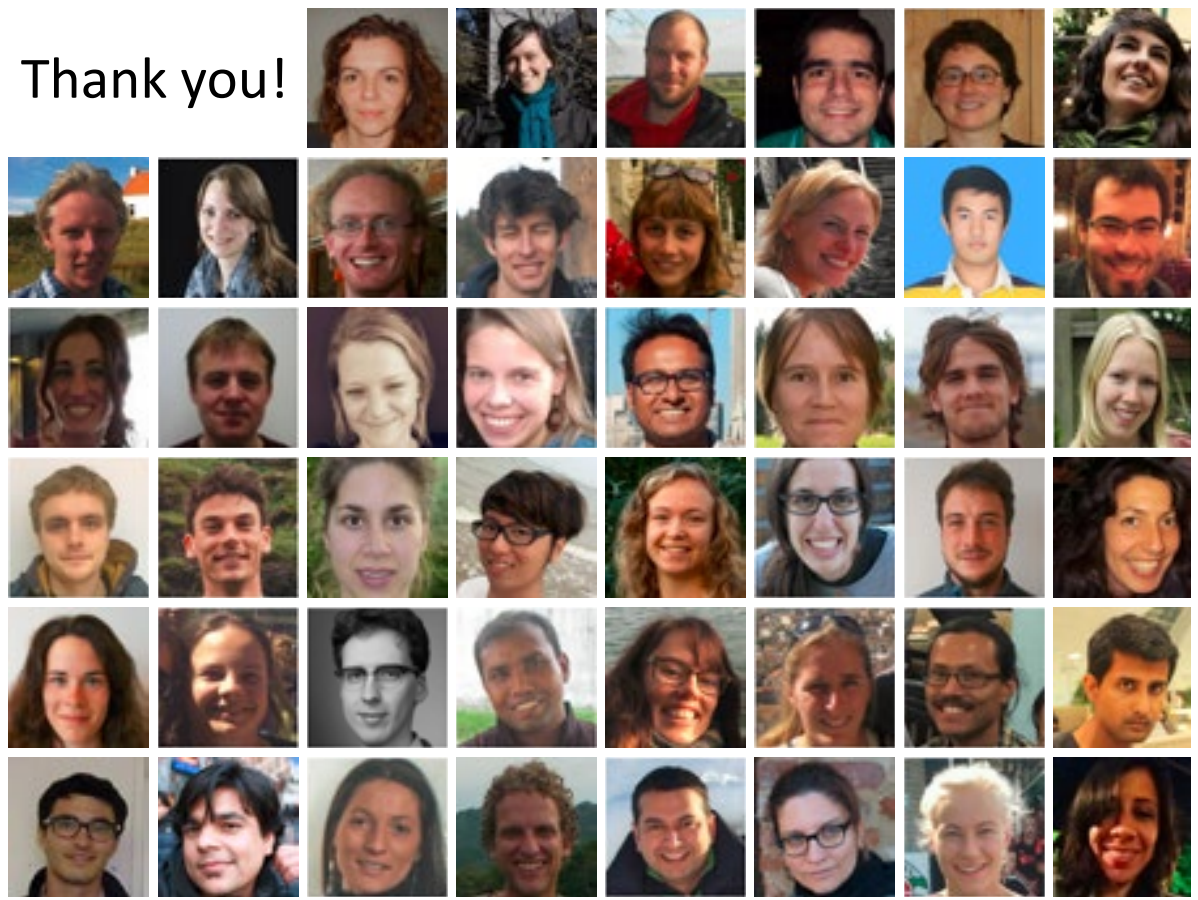

Figure 14. Some (but by no means all) of the Bsc, MSc, PhD students and postdocs that helped me achieve my research goals during my career so far.

by gently twanging a garden fork or by other means. The championship is inspired by similar events organized in the United Kingdom - where else? Rather silly modes of operation, or interesting dress, are certainly not discouraged. Events organized in the UK have taught us that, besides great fun, this is an excellent way to familiarize the general public with the importance of soil life.

\section{Teaching as an integral part of my research programme}

It is customary in an inaugural lecture that the new professor makes some statements about teaching, and perhaps you were wondering when I would do that. Well, to be honest, I have talked about teaching already for the last 35 minutes or so. I hope you have noticed that almost all of the results I have shown are from research carried out by Bachelors, Masters, or PhD students in my group - I counted at least 12, but I could have shown many more exciting examples. I have enough interesting results collected by students for at least three more inaugural lectures!

I am particularly proud to have supervised a very large number of excellent, well-motivated students and postdocs to help me with my research in the years leading up to today (Figure 14). They say that it takes a village to raise a child: I would 
add to that that it takes a classroom to raise a professor - or, at least, this professor.

I also teach courses, and I am very happy to coordinate and teach with my colleagues the course 'Biological Interactions in Soils'. In this course we teach the topic I talked about during the last 35 minutes: the importance of soil biota in modulating the interactions between the soil, nutrients and plants. In this course, which is highly appreciated by students, we are facing a challenge that is very familiar to most Wageningen teachers: how to accommodate the rising number of students that is not accompanied by increased funds for teaching?

This is a serious threat for the highly successful Wageningen style of teaching, which is characterized by personal contact with students and high teacher / student ratios. In our course we had to increase the maximum number of students from 30 to 6o, and I think we did quite well. We did so by introducing elements of gamification, flipped classroom tutorials as well as virtual practicals. The students were very enthusiastic about this new setup of the course, and so were we. I think that in a way we have managed to square the circle, and I'm highly motivated to keep adapting our courses to accommodate more students in the coming years while keeping the essence of the successful Wageningen teaching style intact.

\section{Teaching as knowledge utilization}

However, I am very concerned about the quality of teaching at the Dutch universities, as I think there are powerful incentives against teaching for young talented scientists.

For example, NWO (Netherlands Organisation for Scientific Research), one of our main funding sources, now demands that we include a so-called 'knowledge utilization' paragraph in our research proposals. In this paragraph we have to explain in what way, and over what time period, our research will benefit society. This paragraph is graded separately and counts for approximately $20 \%$ of the ranking of the proposal. Given the highly competitive nature of NWO grants, an excellent knowledge utilization score is indispensable for a succesfull proposal.

However, teaching at a university, a highly time-consuming key task for any university staff member, is not explicitly taken into account when proposals are ranked. The committee can make its own assessment of the scientists' $\mathrm{CV}$, and in practice a substantial teaching load is often considered to be time lost for research. Therefore, if a talented young scientist asks me what to do in order to succeed in science, I almost feel I have to say "teach as little as possible. Try to avoid teaching at university or get a position at an institute where you don't need to teach."

This needs to change if we want to safeguard the quality of our universities. Surely, if NWO can take into account knowledge utilization of the proposals we write, they can also take into account teaching? After all, is transfer of knowledge not the greatest knowledge utilization of all for a university staff member? 
$\underline{\text { Veni / vidi / vici proposals: }}$

- Quality scientist (40\%)

- Quality proposal (40\%)

- Knowledge utilisation (20\%) .... OR ....

- Quality teaching record (20\%)

\section{Open round proposals:}

- Originality proposal (33\%)

- Quality proposal (33\%)

- Quality researchers (17\%)

- Knowledge utilisation (17\%) .... OR ....

- Quality teaching record (17\%)

Figure 15. The current criteria used in ranking NWO Veni / vidi / vici proposals (left) and NWO open round proposals (right), in black, with their relative weighing. The potential for knowledge utilisation counts for $20 \%$ resp. $17 \%$ in the ranking, and teaching is not taken into consideration. In green my proposal for equating a high-quality teaching record with a knowledge utilisation paragraph.

I think that, for proposals submitted to NWO, a serious, well documented, high quality teaching record should be considered a good substitute for a knowledge utilization paragraph, and count equally for $20 \%$ of the proposal ranking (Figure 15). If scientists submitting a proposal do not teach, then they should explain in which way and over what time period their work will benefit society. But if the scientist has a substantial and highly-evaluated teaching record, then this should be obvious without further explanation.

I recognize that, in this day and age, science has to give account for the public money that it spends and show how it benefits society. But let's do so without creating perverse incentives against teaching.

\section{Take-home message}

I have a take-home message, and because everybody who is anybody nowadays uses Twitter as the main mode of communication, I made sure that it fits within 144 characters:

As soil ecologists working in agricultural systems, we should be inspired by nature, but not blinded by nature.

If we don't do that, we might on the one hand be disappointed by the effects of soil 
biota as we overestimate them; but on the other hand we may also miss important beneficial novel roles of biota in agricultural systems. I repeat here the two main questions I want to address in this respect:

1 What are the exact processes by which soil biota affect nutrient cycles in intensively managed systems?

and

2 Can they help to make agriculture more sustainable?

I hope that with this inaugural lecture I have convinced you that I should do this by focusing on the shifting roles of soil fauna and plant roots in agricultural systems; and by working closely with soil chemists; soil physicists; and agronomists.

What might be less clear from the very first part of my lecture is that I intend to focus my research mostly on the planet Earth. Mostly, but not exclusively.... Because over the last few months we have been doing a pilot experiment with our colleagues from Wageningen Environmental Research (WEnR). Wieger Wamelink has shown that on Mars-like soils, you can grow plants and that can you can eat those plants without health risks. We have now taken his research a step further and studied whether earthworms might survive in these soils and might help to make agriculture in a future expedition to Mars possible. I'm very happy to report here today that earthworms seems to thrive in these Mars-like soils. In fact, I am proud to report that we found an earthworm cocoon in one of our mesocosms with these soils. So, although I cannot announce today that we discovered life on Mars (what a memorable inaugural lecture that would make!), I can announce that we discovered that higher life might survive on Mars.

So, am I, a soil ecologist, volunteering to join the botanist on a future mission to Mars? No, thank you - but I think it would be a grand idea for such an expedition to take some earthworm cocoons.

\section{Acknowledgements}

I have already thanked my students, but there are many others that I also would like to acknowledge. First of all, all my co-authors over the years - I cannot mention you all in person, but here you all are, with my most regular co-authors in larger font size (Figure 16). Thank you for your expertise and your collegiality - I would not stand here without you. Next, I would like to thank Alfred Stein and Johan Bouma, my co-promotor and promotor, for being my mentors during my important formative years as researcher.

Thanks to all my colleagues from UC Davis, Alterra/WEnR and the Department of 


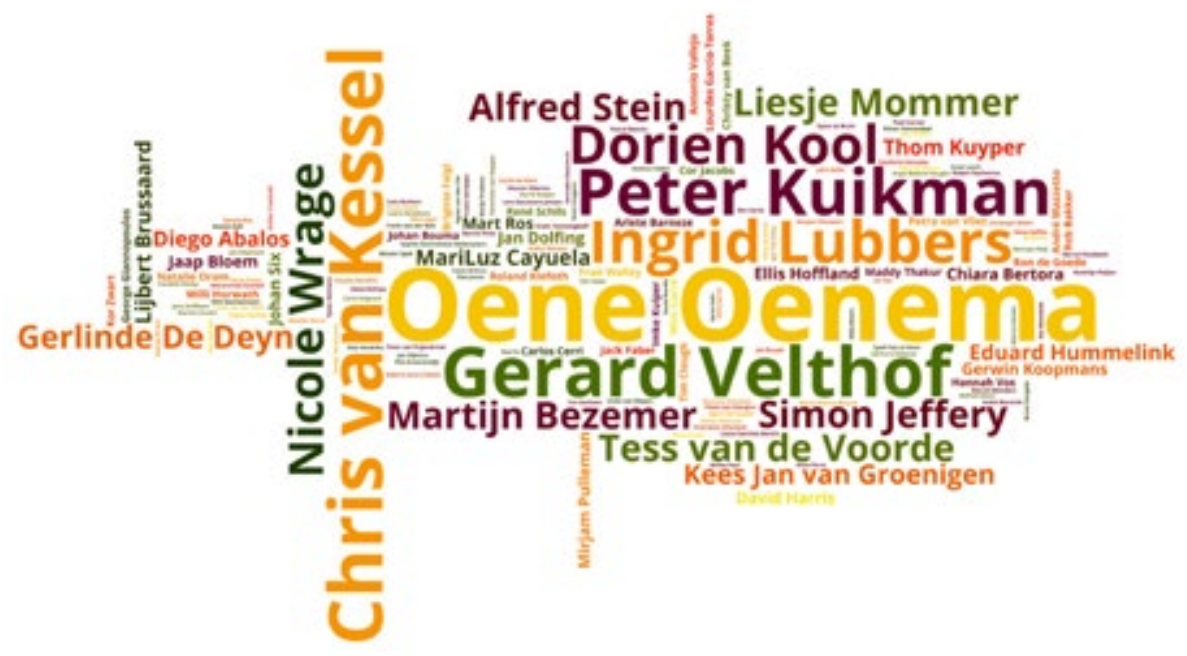

Figure 16. Thanks to all my co-authors of the peer-reviewed papers I published over the years! Font size reflects the number of jointly published articles.

Soil Quality - the scientific staff, the lab staff as well as the administrative staff. In particular, I would like to thank Lijbert Brussaard for convincing me to write a Vidi proposal and come to the university from Alterra, which in many ways marked the start of my current research programme. Sometimes all one needs is a small but decisive nudge in the right direction, and you were the one who gave it. I would also like to thank you for your sincere support in the process leading up to this day.

Recently you have been succeeded by Rachel Creamer. Rachel, although I have only known you for a short period, I certainly appreciate your open and inclusive leadership style, and I am sure we will find many interesting projects to cooperate on in the future.

Many thanks to Oene Oenema for many joint research projects since I moved to Wageningen - Oene, your name is printed in the largest font size in Figure 16, and with good reason. I have always been amazed by the breadth of your knowledge; you are the best person to ask about policy directives from Brussels, but I also come to you when I want to know the average milk production per cow, or trends in the phosphorous content of manure over the last decades in the Netherlands versus, let's say, northern Italy. I admire your seemingly effortless capacity for working very hard and effectively, particularly as you combine it with an eternal sunny disposition. It is a combination that I can only dream of.

I would like to thank Gerlinde De Deyn, my partner in crime in many of my current research projects, my roommate, and the main reason that my day is never boring, or too structured, ... or, sometimes, particularly productive.... I owe Gerlinde and Thom Kuyper special thanks for teaching the course 'Biological Interactions in 
Soils' with me - teaching this course was and is a great pleasure, and it has done more to make me a soil ecologist than anything else could have.

Many thanks to Wim van Egmond, who not only makes the invisible soil life visible, but also shows how beautiful it is. Perhaps more than anyone, you have helped in showing the larger public the importance of our work. You are also one of the most sincere and selfless persons I know, and that is inspiring in itself. Thanks for all the amazing pictures and time-lapse movies, including the title page illustration of this booklet.

Special thanks are for Chris van Kessel, my advisor when I worked at UC Davis and my mentor and friend ever since. Chris, some people have shown me how you can be an excellent researcher; others how you can be a good scientific manager. You, more than anyone, have shown me what it means to be truly a scientific leader - and at the same time, how you can be one without losing your enthusiasm or a slightly mischievous streak. It is an example that I will always keep in mind.

Het laatste, belangrijkste, dankwoord, is voor iedereen die belangrijk voor me is, en is geweest, buiten mijn werk. Ik hoef jullie hier niet bij naam te noemen; jullie weten wie je zijn. Ik weet niet of ik hier zonder jullie had gestaan - maar dan was ik in ieder geval een heel ander mens geweest, en ik ben heel blij dat dat niet zo is. Dank jullie wel!

\section{Conclusion}

Before I end I want to go back once more to the dust bowl. Very few good things came out of that horrible episode, but one of them was the novel 'The Grapes of Wrath' by John Steinbeck. In this novel, which won him the Nobel Prize in Literature, Steinbeck describes in vivid terms the almost mystical connection between farmers and soil, which according to him broke down with the onset of modern agriculture. I would like to end with a quote from this novel, with a message that not only farmers but especially soil scientists should always keep in mind:

"... for nitrates are not the land, nor phosphates; and the length of fiber in the cotton is not the land. Carbon is not a man, nor salt nor water nor calcium. He is all these, but he is much more, much more; and the land is so much more than its analysis..."

Mijnheer de Rector; ik heb gezegd. 


\section{References}

Abalos D., G.B. De Deyn, Th.W. Kuyper, and J.W. van Groenigen (2014) Plant species identity surpasses species richness as a key driver of $\mathrm{N}_{2} \mathrm{O}$ emissions from grassland. Global Change Biology 20:265-275.

FAO (2012) World Agriculture Towards 2030/2050: The 2012 Revision. Food and Agriculture Organization of the United Nations, ESA Working Paper No. 12-03. Lubbers I.M., K.J. Van Groenigen, S.J. Fonte, J. Six, L. Brussaard, and J.W. van Groenigen (2013) Greenhouse-gas emissions from soils increased by earthworms. Nature Climate Change 3:187-194.

Porre R.J., J.W. van Groenigen, G.B. De Deyn, R.G.M. de Goede, and I.M. Lubbers (2016) Exploring the relationship between soil mesofauna, soil structure and $\mathrm{N}_{2} \mathrm{O}$ emissions. Soil Biology and Biochemistry 96:55-64.

Rockström J., W. Steffen, K. Noone, et al. (2009) Planetary boundaries: exploring the safe operating space for humanity. Ecology and Society 14:32.

Ros M.B.H., T. Hiemstra, J.W. van Groenigen, A. Chareesri, and G.F. Koopmans (2017) Exploring the pathways of earthworm-induced phosphorus availability. Geoderma 303:99-109.

Science (2004) Soils: the final frontier. Science (special issue) 304.

Van Groenigen J.W., E.G. Burns, J.M. Eadie, W.R. Horwath, and C. Van Kessel (2003) Effects of foraging waterfowl in winter flooded rice fields on weed stress and residue decomposition. Agriculture, Ecosystems and Environment 95:289-296.

Van Groenigen J.W., I.M. Lubbers, H.M.J. Vos, G.G. Brown, G.B. De Deyn, and K.J. van Groenigen (2014) Earthworms increase plant production: a meta-analysis. Scientific Reports 4:6365.

Vos H.M.J., L. Beezemer, G.F. Koopmans, R.G.M. de Goede, T. Hiemstra, and J.W. van Groenigen (2017) Large variation in cast properties of earthworm species: the link to soil phosphorus. To be submitted to Soil Biology and Biochemistry.

Vos H.M.J., M.B.H. Ros, G.F. Koopmans, and J.W. van Groenigen (2014) Do earthworms affect phosphorus availability to grass? A pot experiment. Soil Biology and Biochemistry 79:34-42. 



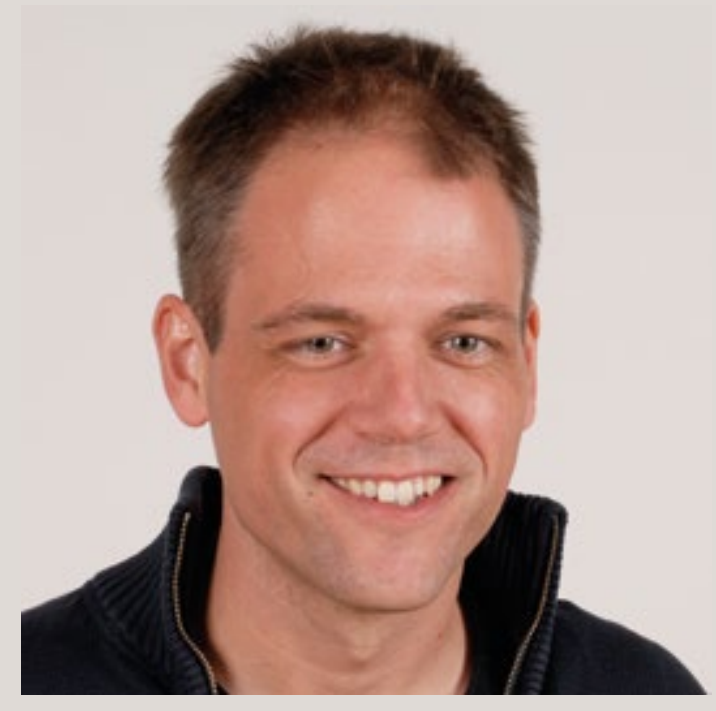

Prof. dr Jan Willem van Groenigen

"As soil ecologists we should be inspired by nature and use our knowledge to improve agricultural systems. We should be inspired by nature, but not blinded by it, because there are many instances where the rules of nature do not translate so well to agriculture. It is these shifting roles of soil biota in agriculture that I intend to study - as a soil ecologist I am fascinated more by the differences between agriculture and nature, than by their similarities." 